\title{
Comparison of Serological and Physiological Classification of the Genus Saccharomyces
}

\author{
By I. CAMPBELL \\ Department of Brewing and Biochemistry, Heriot-Watt University, Edinburgh
}

(Accepted for publication 2 July 1970)

\section{SUMMARY}

The physiological and morphological properties of 28 species of the genus Saccharomyces were subjected to numerical analysis. Ten groups were distinguished, which agreed well with serological groupings, thus: (I) S. bailii, $S$. bisporus, $S$. mellis and $S$. rouxii, of serological group A; (2) S. carlsbergensis and $S$. cartilaginosus (A); (3) S. cerevisiae (AB); (4) S. oviformis, $S$. steineri and $S$. veronae (AC) and S. bayanus and S. pastorianus (C); (5) $S$. acidifaciens and $S$. elegans (AD); (6) S. fragilis and S. marxianus (B); (7) $S$. chevalieri (BC); (8) S. cerevisiae var. ellipsoideus, $S$. diastaticus, $S$. logos, $S$. uvarum, S. willianus and a further group of strains of $S$. carlsbergensis (all of group C); (9) S. fermentati, S. microellipsodes and S. rosei (D); (Io) $S$. delbrueckii (D).

Serological classification offers results sufficiently close to those obtained by morphological and physiological tests to provide a rapid and reliable method of identification of Saccharomyces species.

\section{INTRODUCTION}

A simple serological classification of the genus Saccharomyces, using four absorbed sera, has been described previously (Campbell, I968). However, in some instances the serological classification does not coincide with the identification by the standard morphological and physiological tests of Lodder \& Kreger-van Rij (1952). For example, there are two antigenically distinct subgroups of $S$. carlsbergensis, termed I and II by Campbell \& Brudzynski (1966), and of $S$. cerevisiae, but in the latter case the antigenic variant closely corresponds to the morphological variant ellipsoideus (Campbell \& Allan, 1964). Another discrepancy between generally accepted classification and the serological method is the large group of species, including $S$. carlsbergensis II, $S$. cerevisiae var. ellipsoideus, $S$. logos, $S$. uvarum and $S$. willianus, which are antigenically identical (Campbell, 1968).

Kockova-Kratochvilova \& colleagues (1966 $a, b, 1967,1968)$ have demonstrated by numerical taxonomy of many species of Saccharomyces that certain species recognized by Lodder \& Kreger-van Rij (1952) do not on full analysis justify specific rank. Saccharomyces pastorianus, $S$. bayanus and $S$. willianus were sufficiently similar to be grouped as one species, $S$. heterogenicus was significantly different from that group, but $S$. steineri formed a transition between them (Kockova-Kratochvilova, VojtkovaLepsikova, Sandula \& Pokorna, 1968).

In the present paper an analysis of 28 Saccharomyces species is presented in order to examine fully the compatability of our serological identification scheme with the Lodder \& Kreger-van Rij system, and with the condensed classification proposed by Kockova-Kratochvilova et al. (1968). 


\section{METHODS}

Yeast cultures. Cultures of 28 Saccharomyces species were obtained from the National Collection of Yeast Cultures (NCYC), Nutfield; additional strains were isolated in this Department or obtained from other sources. The total of 136 cultures were identified on isolation or receipt by the system of Lodder \& Kreger-van Rij (1952). Cultures were normally grown at $25^{\circ}$ for 3 days; those for preparation of antisera and inoculation of identification tests were prepared on Sabouraud glucose agar (Oxoid).

Characters for numerical analysis. The 48 tests described below were performed on each strain.

Morphology (9 characters). Cells, grown in malt extract broth, were assessed as spherical (length up to $\mathrm{I} \frac{1}{2} \times$ breadth), oval $\left(\mathrm{I} \frac{1}{2}\right.$ to $3 \times \mathrm{I}$ ) or long-oval (over $3 \times \mathrm{I}$ ); small (width up to $4 \mu \mathrm{m}$.) or large (width over $4 \mu \mathrm{m}$.). Production of pseudomycelium (slight, up to 5 cells long; extensive, over 5 cells) on Oxoid cornmeal agar was assessed without regard to morphology; for this and other tests on solid media nine cultures were conveniently spotted on one $10 \mathrm{~cm}$. diameter plate. Colony morphology on malt extract agar was assessed after 3 days as smooth (circular outline, glossy surface) or rough (irregular outline, matt or rough surface).

Physiology (35 characters). Suspensions of cells from Sabouraud agar were prepared in $0.1 \mathrm{M}$-phosphate buffer, $\mathrm{pH} 6$, washed by centrifugation and incubated at $25^{\circ}$ in the same buffer for $2 \mathrm{~h}$. to deplete intracellular reserves of nutrients. After two further washings the suspensions were adjusted to approximately $10^{7} \mathrm{cells} / \mathrm{ml}$. and the test media inoculated with $0.02 \mathrm{ml}$. of suspension. All tests were performed in duplicate or triplicate on separate occasions. Fermentation and assimilation of galactose, sucrose, maltose, raffinose, lactose, melibiose and maltotriose (Lodder \& Kreger-van Rij, 1952; Gilliland, 1956) were tested by the method of Campbell \& Brudzynski (1966). Maltotriose, added at $3 \%$ to the basal medium, was prepared by hydrolysis of pullulan (Ueda, Fujita, Komatsu \& Nakashima, 1963) by pullulanase (Bender \& Wallenfels, I96I). Assimilation alone of sugars was scored +- . Fermentation, which included assimilation, was scored ++ , except in the case of maltotriose when only fermentation was scored as + . No distinction was made between partial and complete fermentation of raffinose. Assimilation of ethanol, glycerol or L-arabinose, each at $2 \%$, as sole carbon source, and of $0.25 \%$ glycine, L-histidine, L-lysine, Lmethionine or L-tryptophan as sole nitrogen source (Wickerham, 1952) were tested on the appropriately supplemented Difco yeast nitrogen or carbon medium, solidified with $\mathbf{I} \%$ Oxoid agar no. I. In addition to growth on tryptophan, cultures were examined for producton of a brown halo which was observed to surround the colonies of certain species on tryptophan agar. Requirements for vitamins (Schultz \& Atkin, 1947) were assessed in terms of 'bios factors' I, 2, 3 and 6 (inositol, pantothenate, biotin and pyridoxine + thiamine) on agar based on the formula for Difco yeast vitamin medium but prepared from salts and amino acids supplied by B.D.H. Chemicals Ltd (Poole, Dorset) and vitamins by Koch-Light Ltd (Colnbrook, Buckinghamshire).

As additional identification tests, the following were examined: growth in malt extract broth containing $8, \mathrm{I} 2$ or $16 \%(\mathrm{v} / \mathrm{v})$ ethanol (added aseptically to sterile broth) and growth under conditions of high osmotic pressure in a medium of $20 \mathrm{~g}$. glucose, $5 \mathrm{~g}$. $\mathrm{NaCl}$ and I g. Oxoid mycological peptone per Ioo ml. ('Osmophilic medium') 
(Kockova-Kratochvilova et al. 1966 ) and at 30 and $37^{\circ}$ over 2 days on malt extract agar. Lipolysis was detected on Oxoid tributyrin agar and acid production on the chalk agar described by Lodder \& Kreger-van Rij (I952). Strains were also tested for growth in the presence of 20 p.p.m. crystal violet (Kato, 1967).

Flocculation and fining (4 characters). These properties were assessed as described by Campbell, Robson \& Hough (1968) and each scored,--+- or ++ .

Table I. Antigenic structure of various Saccharomyces species

$\begin{array}{lc}\text { Species and NCYC* numbers } & \begin{array}{c}\text { Antigenic } \\ \text { structure }\end{array} \\ \text { Saccharomyces bailii } 385,580 & \text { A } \\ \text { S. bisporus } \mathrm{I} 7 \mathrm{I}, 697 & \mathrm{~A} \\ \text { S. cartilaginosus } 76 & \mathrm{~A} \\ \text { S. mellis } 4 \mathrm{I} 8 & \mathrm{~A} \\ \text { S. oviformis } 374,482 & \mathrm{AC} \\ S . \text { steineri } 406,70 \mathrm{I} & \mathrm{AC} \\ S . \text { fructuum } 4 \mathrm{I0}, 609,620 & \mathrm{C} \\ S . \text { heterogenicus } 4 \mathrm{I} 5,484 & \mathrm{C} \\ S . \text { italicus } \mathrm{I} 08 & \mathrm{C} \\ S . \text { microellipsodes } 698 & \mathrm{D} \\ \text { S. rosei } 566,585 & \mathrm{D}\end{array}$

* National Collection of Yeast Cultures, Nutfield, Surrey.

Numerical analyses. Properties, other than serological, were recorded on 80-column punched cards and the percentage similarity between strains calculated on an I.C.L. 4I 30 computer. Both positive and negative matches were assessed as similarity, using the formula for $S_{s}$ of Sneath (1962). Similarity matrices and thence dendrograms were prepared as described by Sneath (I962), plotting results at $5 \%$ intervals. Relationships between groups of strains were drawn at the highest mutual similarity level, as at lowest or mean similarity level the differences between groups were unjustifiably enhanced. Normally the percentage similarity between strains in a cluster fell within a $5 \%$ range.

Since the large number of strains involved in the project could not be handled conveniently in a single run of the computer, sets of up to 20 strains of similar serological properties were processed together, and compared in turn with a similar number of strains of other serological groups. Thus all strains of species of serological group A (Saccharomyces bailii, S. bisporus, S. carlsbergensis I, S. cartilaginosus, $S$. mellis and $S$. rouxii) (Campbell, I968; see also Table I) were compared in successive analyses with groups of strains of serological groups $\mathrm{AB}, \mathrm{AC}, \mathrm{AD}, \mathrm{B}, \mathrm{BC}, \mathrm{C}$ and $\mathrm{D}$, which were compared in turn with all other groups. A small number of strains were chosen of each species to confirm in a final survey the relationships indicated by the preliminary findings.

\section{RESULTS}

Serological properties of species. All available strains of 28 Saccharomyces species were tested by absorbed antisera A, B, C and D (Campbell, 1968). Agglutination patterns of species not classified in the earlier communication are listed in Table $\mathrm{I}$. In addition, sera were prepared against at least one strain of each species not tested previously. On analysis by a full programme of absorption tests with strains of various antigenic groups, no antigenic factors additional to those already listed in Table I were 


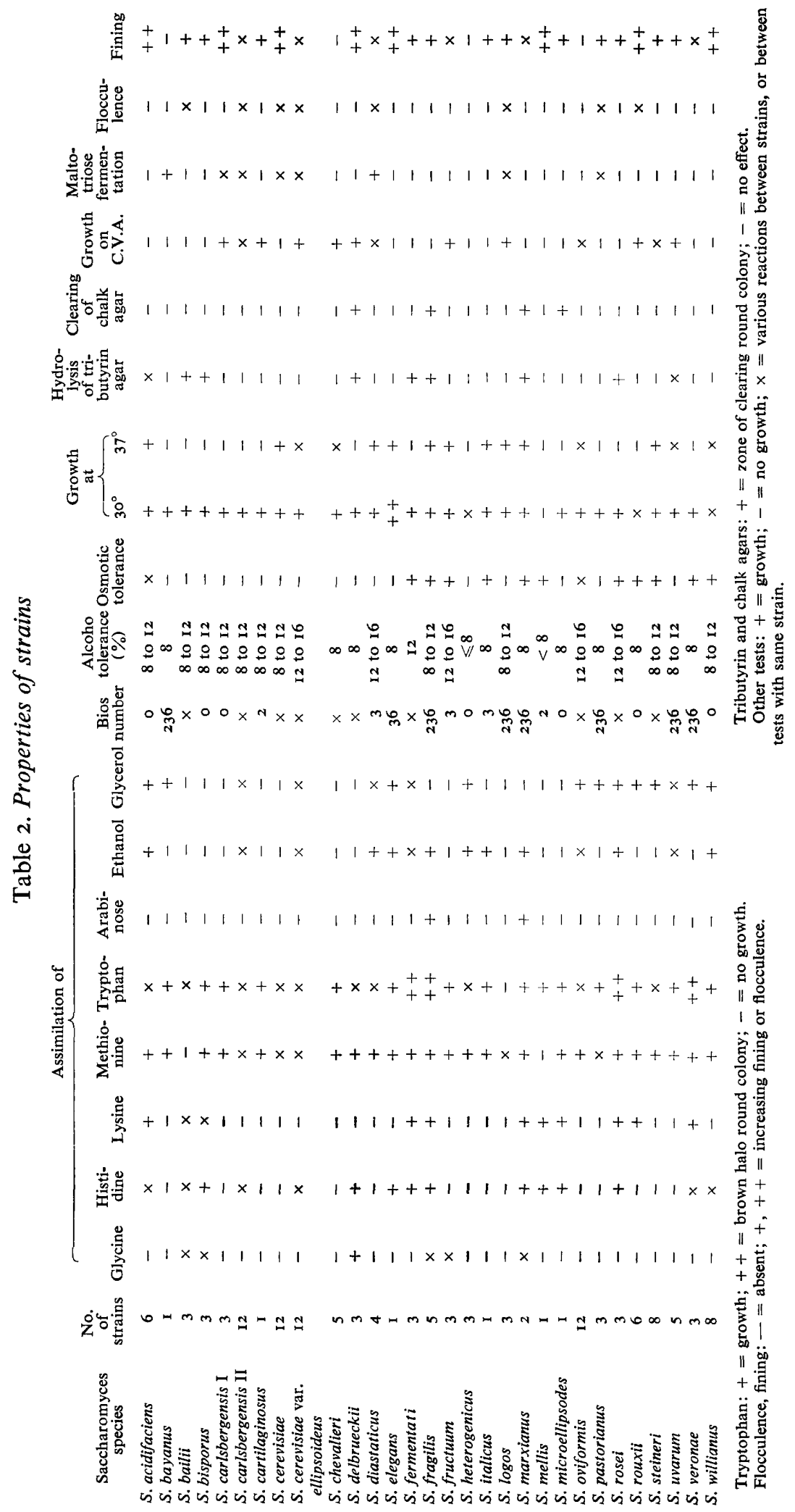




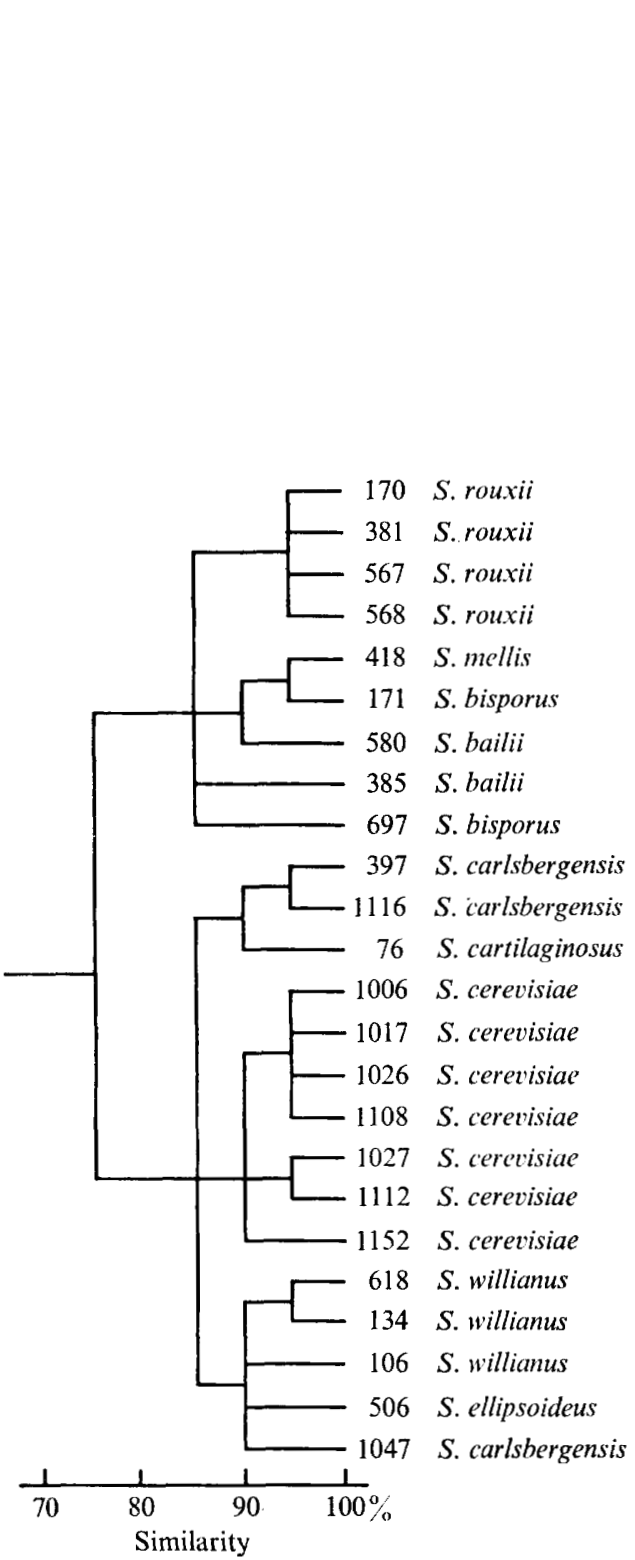

Fig. I

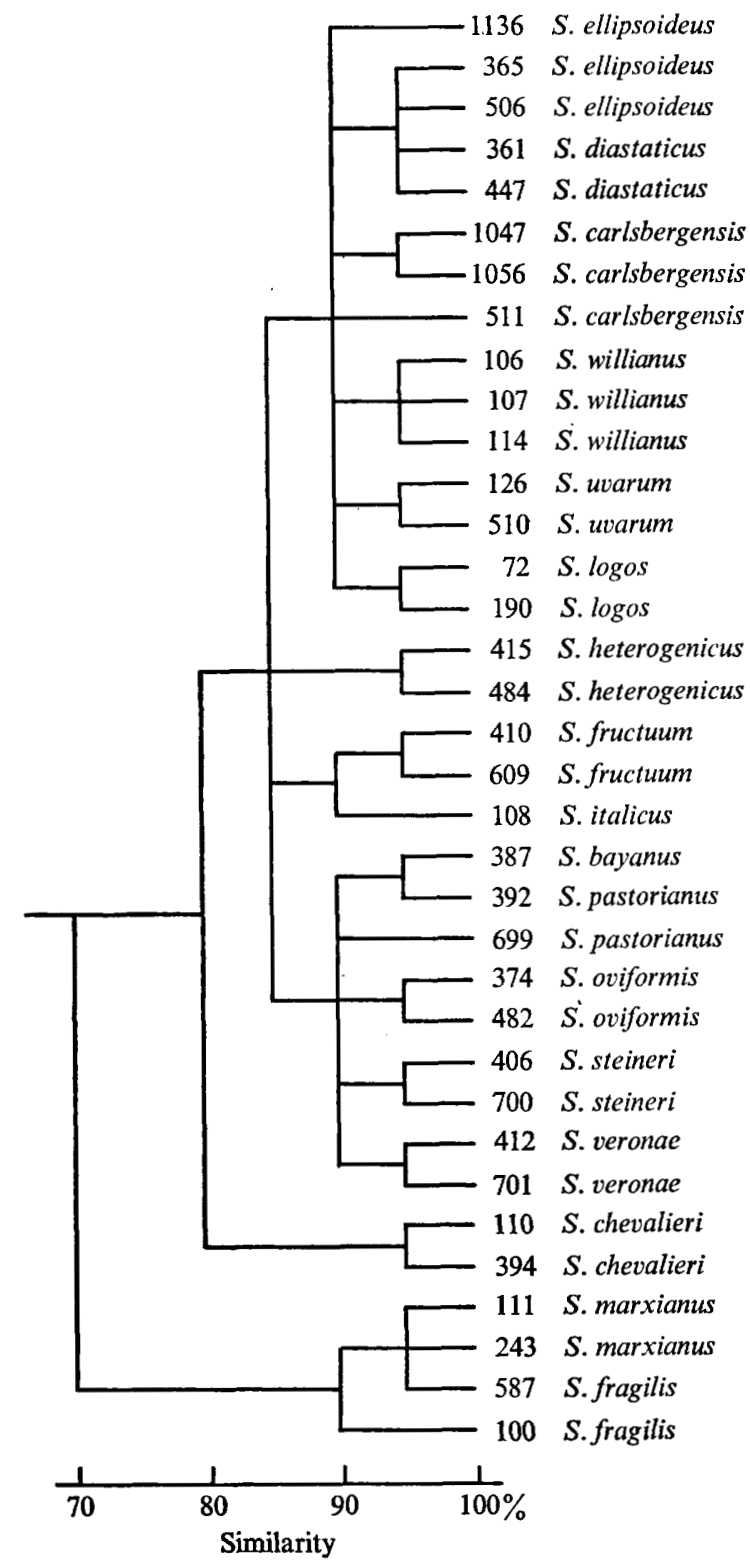

Fig. 2

Fig. I Dendrogram of typical NCYC strains reacting with serum A, and selected group C strains (Saccharomyces carlsbergensis 1047, S. ellipsoideus 506 and S. willianus 106) for comparison.

Fig 2. Dendrogram of typical NCYCstrains reacting with serum B(Saccharomyces marxianus and $S$. fragilis) and serum $\mathrm{C}$ (other species). 
found. Sera to Saccharomyces oviformis and S. steineri agglutinated cultures of both groups $\mathrm{A}$ and $\mathrm{C}$; absorption by a culture of one group left agglutinating activity to all cultures of the other group. All species agglutinated by serum $\mathrm{A}$, other than $S$. rouxii, were also agglutinated by the serum I described previously (Campbell, 1968). No reactions were noted between the newly examined strains and sera 2, 3, 4 and 5 .

Numerical analyses. The identification tests of Lodder \& Kreger-van Rij (I952) accounted for 20 morphological and physiological characters. Some tests, e.g. fermentation of glucose, were not applicable because of consistently positive results in the genus Saccharomyces; other tests, e.g. pellicle formation, were consistently negative. The remaining properties of each species are summarized in Table 2. Typical examples of

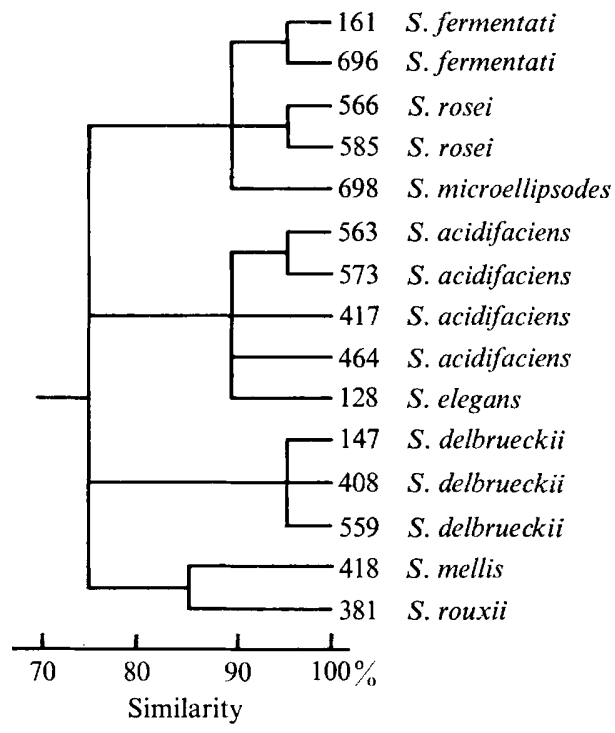

Fig 3. Dendrogram of typical NCYC strains reacting with serum D, and selected group A strains (Saccharomyces mellis 418 and $S$. rouxii 381 ) for comparison.

dendrograms are presented in Fig. I to 3, which show only NCYC strains, although additional strains of most species, from the NCYC and elsewhere, were examined. The total number of strains tested of each species is shown in Table 2.

The relationship between Saccharomyces cerevisiae, $S$. carlsbergensis I, two strains of $S$. willianus and the one strain available of $S$. cartilaginosus, all of which react with serum A, is illustrated in Fig. I. The 90 to $97 \%$ mutual similarity of all strains of $S$. rouxii, and the more distant relationship of other species of serological group $A$ is also shown. However, the small-celled species $S$. bailii, S. bisporus, S. mellis and $S$. rouxii show a percentage similarity of 75 or less to the large-celled species $S$. carlsbergensis and $S$. cartilaginosus which similarly react only with serum A. The ' $S$. carlsbergensis group' shows more affinity to $S$. cerevisiae and the two strains, 134 and 6I8, of $S$. willianus reacting with sera $\mathrm{A}$ and $\mathrm{B}$, but these $S$. willianus strains in turn show a closer similarity to the group C strains of their own species, of which strain 106 appears as an example in Fig. I. Saccharomyces willianus, irrespective of serological properties, is taxonomically closer to $S$. cerevisiae var. ellipsoideus and those strains of $S$. carlsbergensis which react with serum $\mathrm{C}$, than to $S$. cerevisiae. 
Fig. 2 illustrates the close relationship between the strains of groups $\mathrm{AC}$ and C, e.g. the 80 to $85 \%$ similarity between Saccharomyces oviformis (AC) and S. cerevisiae var. ellipsoideus (C). Saccharomyces fructuum, S. heterogenicus and S. italicus, serologically of group $\mathrm{C}$, occupy an intermediate position on the dendrogram between the ' $S$.

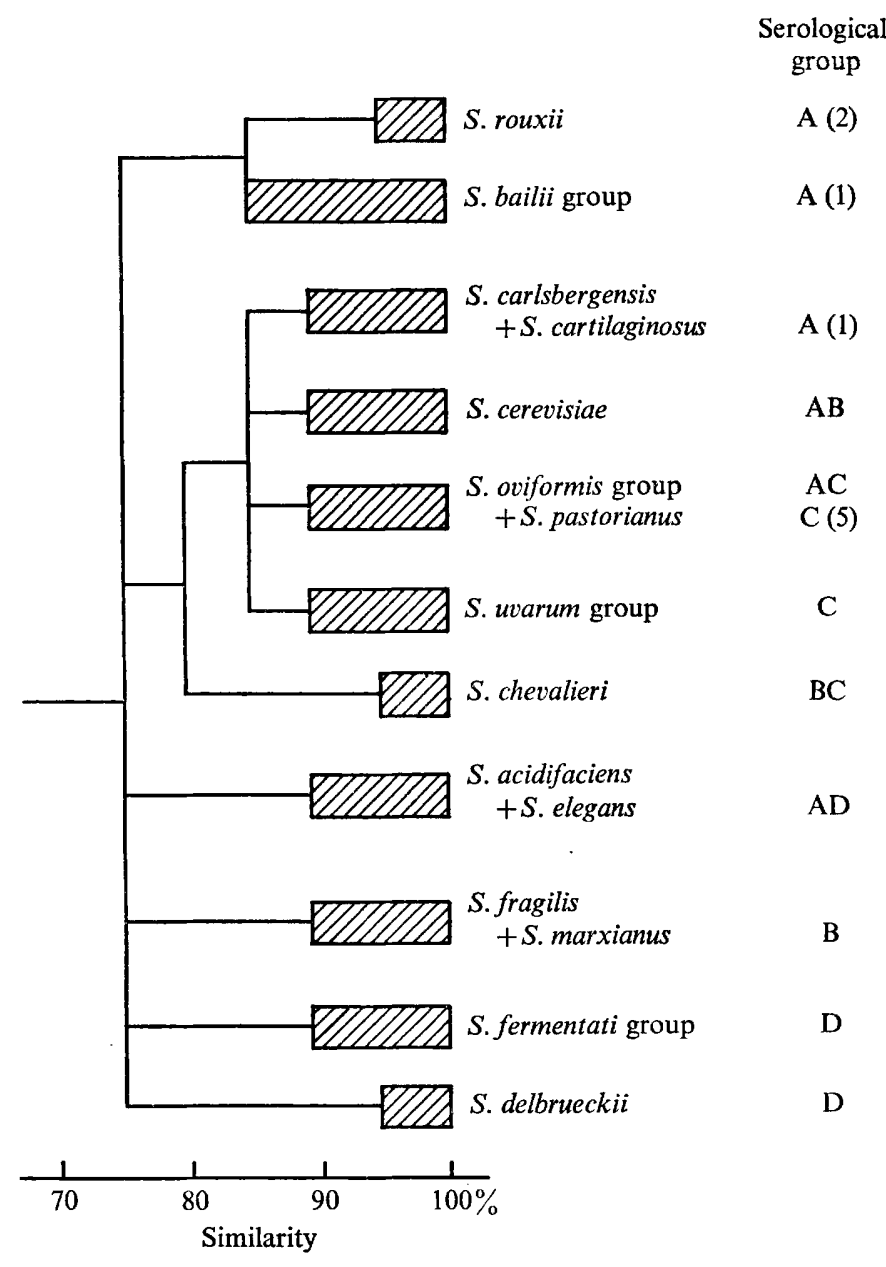

Fig. 4. Dendrogram of all species tested, from NCYC and other sources. Spread of proposed groups is denoted by shading.

carlsbergensis-S. willianus group' (C) and the 'S. oviformis group' (AC), thus producing a large cluster of species with no significant subgrouping. Only $S$. chevalieri and the $S$. fragilis $-S$. marxianus group showed a significant difference from other species shown in Fig. 2, which agrees well with their different serological properties, BC and C respectively.

Fig. 3 shows all NCYC strains which reacted with the specific group D serum. Saccharomyces mellis and $S$. rouxii are included for comparison with organisms of serological group A; both groups are mainly composed of species which ferment few of the sugars tested, or only glucose, but on taking into account all 48 properties the 
similarity between species of serological groups A and D is no more than $75 \%$. Saccharomyces acidifaciens and S. elegans react with both sera A and D, the serological properties reflecting a marked taxonomic difference.

Comparison of serological and physiological groupings. Strains were allocated to distinct groups according to all suitable physiological and morphological tests (Fig. I to 3). In Fig. 4, compiled from a final analysis of representative NCYC strains of each species, or taxonomic group as determined above, the observed groups are compared with our serological classification (Campbell, I968; and Table I above). Distinct groups, corresponding to antigenic properties, include Saccharomyces acidifaciens and $S$. elegans (group AD), $S$. fragilis and $S$. marxianus (B), $S$. chevalieri (BC), and $S$. fermentati, $S$. microellipsodes and $S$. rosei (D). Saccharomyces rouxii forms a taxonomically and serologically distinct subgroup of a group of small-celled poorly fermentative species of serological group A. Saccharomyces delbrueckii, although also of group $\mathrm{D}$, is only distantly related to $S$. fermentati.

\section{DISCUSSION}

Many antigenically identical species (Campbell, I968) have been shown by KockovaKratochvilova et al. (I966a, 1968) to be very similar in general properties. The present report describes an investigation by numerical taxonomy of a full range of Saccharomyces species of which the antigenic structure has been determined by our system using four sera A, B, C and D.

The largest group of Saccharomyces species, reacting with sera A, A and B, A and C, or $\mathrm{C}$ alone, contains the large-celled species actively fermenting a wide range of sugars: glucose, sucrose, maltose, often galactose and raffinose, and occasionally maltotriose. These species are important in the fermentation industries, both as culture yeasts and as contaminants. Antigenically they form four distinct groups, as shown in Fig. 4, but numerical analyses (above, and Kockova-Kratochvilova et al. 1966 a, 1968) show that they are very closely related; all show a similarity by our method of calculation of 80 to $85 \%$ between antigenically different strains and 85 to $90 \%$ between strains of the same antigenic group. The species of antigenic group C, S. carlsbergensis, S. cerevisiae var. ellipsoideus, $S$. diastaticus, $S$. uvarum and $S$. willianus, show a particularly close interrelationship, and instances were noted of strains more closely related to strains of other species than to other strains of their own species, e.g. between $S$. cerevisiae var. ellipsoideus and $S$. diastaticus (Fig. 2).

In Fig. 2 and 4, Saccharomyces pastorianus, S. bayanus and the species reacting with sera $\mathrm{A}$ and $\mathrm{C}$ are grouped separately from those reacting with serum $\mathrm{C}$ only. Although $S$. pastorianus is not agglutinated by serum A, it possesses a more complex antigenic structure than species of the $S$. carlsbergensis-S. willianus 'C-only' group. Campbell (1968) described five minor sera as an aid to species classification; one of these, serum 5, agglutinated $S$. pastorianus, but the 'C-only' group does not react with any of the sera I to 5. Thus the species of simplest antigenic structure are distinguishable by numerical taxonomy from those species reacting with sera $\mathrm{A}$ and $\mathrm{C}$ or $\mathbf{C}$ and 5 .

Saccharomyces carlsbergensis I (of serological group A), $S$. cerevisiae (group AB) and groups $\mathrm{AC}$, including $\mathrm{C}_{5}$, and $\mathrm{C}$ may be valid subdivisions, separable at about $85 \%$ similarity, but the results of Kockova-Kratochvilova et al. (I966a, $b, 1967$, I968) obtained from a similar but not identical series of tests, combined with the above 
observations suggest that the serological groups overlap to form a single large group. It is nevertheless useful, for diagnostic and epidemiological purposes, to subdivide serologically. In our experience, two strains showing a similarity of over $85 \%$ are, almost invariably, serologically identical; conversely, two isolates which are serologically identical are normally over $85 \%$ similar in other respects. The two antigenic types of S. willianus, and the difference between S. delbrueckii and the other species of serological group D, provided the only exceptions, and we have found the rapid serological method a reliable preliminary identification system for Saccharomyces yeasts isolated from spoilt beers, wines and foods. Although our basic system (Campbell, 1968), using only four sera A, B, C and D, gives more limited information than the more comprehensive antigenic analyses of Tsuchiya et al. (I965), it is sufficient for identification within the genus Saccharomyces. Thus any yeast isolate which ferments glucose actively, i.e. overnight at $25^{\circ}$, and is therefore presumed to be of the genus Saccharomyces, is quickly allocated to the appropriate antigenic group by a slide agglutination test. In most cases we found it was sufficient simply to record the isolation of 'S. oviformis type' (group AC), ' $S$. bailii type' (group A), etc. Following the precedent of Beech, Davenport, Goswell \& Burnett (1968), no distinction was attempted between Saccharomyces species and the corresponding species of Candida or Torulopsis, and sporulation was not considered in our numerical analyses.

For more accurate identification, a set of seven sera was necessary: A, B, C and D, and the sera I, 2 and 5. Serum 2 distinguished Saccharomyces rouxii from other species reacting with serum A; also, all other group A species were agglutinated by serum I. Serum 5 separated $S$. pastorianus from the various species which reacted only with serum C. Thus, by agglutination test and a morphological examination of cells, e.g. to distinguish $S$. carlsbergensis or $S$. cartilaginosus from the small-celled species reacting with serum A, the various serological subgroups of the genus Saccharomyces may be rapidly distinguished. The numerical analyses of Kockova-Kratochvilova et al. (1966 a, b, 1967, 1968) and the above results suggest that serological methods reliably identify groups of Sacharomyces species to the limit of taxonomic validity.

It is a pleasure to thank Mr C. J. Crook, Computer Unit, Heriot-Watt University, for preparation of the computer program and punched cards for numerical analyses, Dr J. R. Stark for generous provision of maltotriose, and Miss M. Anderson and Miss A. M. Munro for technical assistance.

\section{REFERENCES}

BeECH, F. W., DAVEnPort, R. R., Goswell, R. W \& Burnett, J. K. (I968). In Identification Methods for Microbiologists, Part B, p. I3I. Edited by B. M. Gibbs and D. A. Shapton. London and New York: Academic Press.

Bender, H. \& WAllenfels, K. (196I). Untersuchungen an Pullulan. II. Spezifischer Abbau durch ein bakterielles Enzym. Biochemische Zeitschrift 334, 79-95.

CAMPBell, I. (1968). Serological identification scheme for the genus Saccharomyces. Journal of Applied Bacteriology 31, 5I 5-524.

Campbell, I. \& Allan, A. M. (1964). Antigenic analysis of Saccharomyces cerevisiae. Journal of the Institute of Brewing 70, 316-320.

CAMpbell, I. \& BRUdZYNSKi, A. (1966). Serological studies on brewing yeasts. Journal of the Institute of Brewing 72, 556-560. 
Campbell, I., Robson, F. O. \& Hough, J. S. (1968). Serological investigation of fining and flocculent yeasts. Journal of the Institute of Brewing 74, 360-364.

GilliLAND, R. B. (1956). Maltotriose fermentation in the species differentiation of Saccharomyces. Compte rendu des travaux du Laboratoire Carlsberg 26, 139-148.

KATo, S. (1967). Measurement of infectious wild yeasts in beer by means of crystal violet medium. Bulletin of Brewing Science, Tokyo 13, 19-24.

Kockova-Kratochvilova, A., Pokorna, M. \& Sandula, J. (I966a). The genus Saccharomyces (Meyen) Reess. I. A group of fermentation type II species completely fermenting raffinose. Folia microbiologica (Praha) II, 188-199.

Kockova-Kratochvilova, A., Pokorna, M. \& Vojtkova-LepSikova, A. (1967). The genus Saccharomyces (Meyen) Reess. III. Typical strains of the species Saccharomyces cerevisiae Hansen var. ellipsoideus Stelling-Dekker. Folia microbiologica (Praha) 12, 42-55.

Kockova-Kratochvilova, A., Vojtkova-Lepsikova, A., Sandula, J. \& Pokorna, M. (1966 b). The genus Saccharomyces (Meyen) Reess. II. Atypical strains of the species Saccharomyces carlsbergensis Hansen. Folia microbiologica (Praha) II, 200-209.

Kockova-Kratochvilova, A., Vojtkova-Lepsikova, A., Sandula, J. \& Pokorna, M. (1968). The genus Saccharomyces (Meyen) Reess. V. Saccharomyces willianus Saccardo, Saccharomyces bayanus Saccardo, Saccharomyces pastorianus Hansen, Saccharomyces heterogenicus Osterwalder, Saccharomyces steineri Lodder \& Kreger-van Rij. Folia microbiologica (Praha) 13, 300-309.

LODDER, J. \& KREGER-VAN RIJ, N. J. W. (1952). The Yeasts, a Taxonomic Study. Amsterdam: NorthHolland Publ. Co.

Schultz, A. S. \& Atkin, L. (1947). The utility of bios response in yeast classification and nomenclature. Archives of Biochemistry 14, 369-380.

SNEATH, P. H. A. (1962). The construction of taxonomic groups. Symposia of the Society for General Microbiology 12, 289-332.

Tsuchiya, T., Fukazawa, Y., Kawakita, S., Imai, M. \& Shinoda, T. (1965). Serological classification of the genus Saccharomyces (III). Japanese Journal of Microbiology 9, I49-159.

Ueda, S., Fuitta, K., Komatsu, K. \& Nakashima, Z. (I963). Polysaccharide produced by the genus Pullularia. I. Production of polysaccharide by growing cells. Applied Microbiology II, 21 I-215.

WicKerHAM, L. J. (1952). Recent advances in the taxonomy of yeasts. Annual Review of Microbiology 6, 317-332. 